\title{
Assessment of Factors Influencing Information Sharing Arrangements using the Best-Worst Method
}

\author{
Dhata Praditya ${ }^{10000-0002-0756-6416]}$ and Marijn Janssen ${ }^{1[0000-0001-6211-8790] ~}$ \\ ${ }^{1}$ Faculty of Technology, Policy and Management. Delft University of Technology. Jaffalaan 5. \\ 2628BX. Delft. Netherlands \\ (D.Praditya, M.F.W.H.A.Janssen) dtudelft.nl
}

\begin{abstract}
Governments and companies exchange various kinds of data. The methods to exchange data are evolving and becoming more and more advanced, supported by the rapid development of information and communication technology (ICT). Although some research has been carried out on the adoption of ICT-based information sharing, there is still very little understanding of enablers for information sharing arrangements between private and public organisations. Developing an information sharing arrangement often requires complex interactions among parties resulting in negotiated arrangements. This paper aims to derive factors of information sharing arrangements by assessing the importance of factors in shaping information sharing from public and private organisations perspectives. Factors found in previous studies were analysed using the Best-Worst method by collecting experts' opinions. While private sector's expert was much focussed on the Perceived Benefits, the public sector's experts considered Trust, Investment, Perceived Costs and Relationship as the most important factors in shaping the information sharing arrangement between public and private organisations. Identifying which factors are crucial in shaping information sharing arrangements can help in reducing potential conflicts during planning, implementation and usage, and bringing benefits to all stakeholders.
\end{abstract}

Keywords: Information sharing, big data, open data, e-government, Interorganisational Information System (IOS), information sharing arrangement, system architecture, system governance, best worst method

\section{Introduction}

In the era of big data, more and more emphasis is put on information to support better decisions [1]. For this reason, information sharing intra and interorganisational are required. Interorganisational information arrangements are typically more complex system compared to intraorganisational, because these arrangements have to deal with a variety of stakeholders, multi-level interactions, vertically and horizontally, which makes it is more difficult to reach negotiated solutions [2].

Pardo et al. [3] highlighted the importance of understanding factors influencing the adoption of interorganisational information sharing. Consequently, many studies have 
been investigating factors affecting the interorganisational information sharing $[4,5$, $6,7]$, and especially involving public and private organisations $[8,9,10,11]$.

Work on information sharing have been conducted in various domains, including supply chain $[12,13]$, public safety network [14, 15], disaster management $[16,17]$ and financial reporting system $[18,19]$. These studies emphasized several challenges that complicates the implementation and adoption of information sharing arrangements. These challenges ranging from organisational aspects, such as difference viewpoints, goals, organisational structure, and the availability of resources, to technological aspects, such as interoperability, IT complexity, IT maturity and IT capability [20]. Moreover, there is also imbalance of benefits perceived between stakeholders, one stakeholder might profit, whereas another might bear the cost, which might add complexity and could result in unwillingness to join the project.

To deal with the aforementioned challenges, a proper arrangement which can bridge the interest of the involved stakeholders needs to be developed. An information sharing arrangement can be conceptualised by the interplay between system architecture for information sharing and its accompanying governance [18]. There is a whole range of factors influencing the shape of an information sharing arrangement.

The selection of information sharing arrangement factors can be considered as a type of Multi Criteria Decision Making (MCDM) problem since it influenced by several factors. It is crucial to know which factors influence the shaping of an information sharing arrangement to a large extent and which factors have less influence. This paper aims to derive factors of information sharing arrangements by assessing the importance of factors in shaping information sharing collected from previous studies. To reach that objective, a MCDM method called Best-Worst Method (BWM) was applied in analysing the expert's opinions. The experts were selected from both private and public organisations as well as academia. This results in a list of weighting factors from both the public and private sectors perspective.

BWM is a relatively new method in MCDM area [21]. BWM uses a pairwise comparison to find the optimal weights of the criteria and their consistency ratios. BWM can produce highly consistent and reliable results in more efficient way by provides a pairwise comparison using two vectors instead of a full pairwise matrix and by using only integer value [22]. By using these two characteristics, the result will be reliable even using a few respondents and easier to interpret compared to other methods that utilising fractions. According to [21], BWM is statistically better than AHP (Analytic Hierarchy Process) in term of the consistency ratio, minimum violation, total deviation and conformity.

Understanding which factors and how important they are in arranging information sharing can be beneficial for involved public and private organisations as well as potential users. This can help them to focus on the factors that matter during the development of an information sharing arrangement. The results of this research can be used as a point of reference to reduce potential conflicts which may occur between organisations during negotiating processes. This can increase the acceptance and usage of the system, and bringing benefits to all stakeholders.

This document is structured as follows: the literature review is presented in the next section, including the explanation of information sharing between public and 
private organisations, and its arrangements. Following that, the research methodology is described. Next, the findings of the research are provided, followed by the discussion of the findings. Finally, conclusions, which consists of contributions of the paper, limitations of the research and future research directions are presented.

\section{Literature Review}

\section{Information Sharing between Public and Private Organisations}

Based on [23], [16] and [10], information sharing between public and private organisations is defined as an act to exchange data through a mutual agreement with the objective to improve public services and organisation performances for involved government agencies and private organisations. Points to be underlined are that enabling the information sharing requires agreements, and the implications of information sharing for public and private organisations should be considered. Further in this study, information sharing refers to above definition.

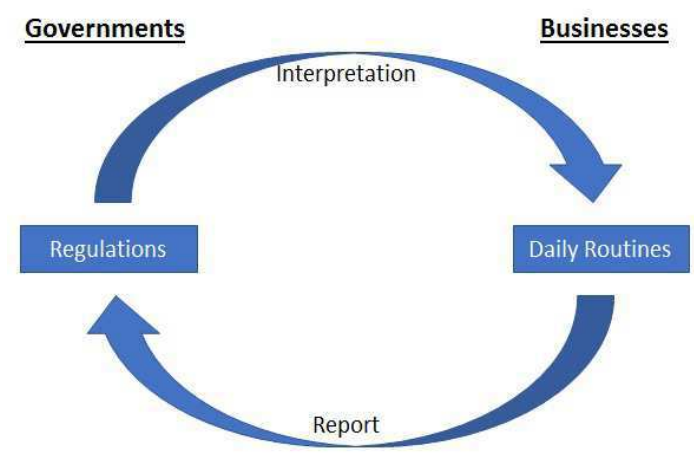

Fig. 1. High-level conceptualisation of Information Sharing between Governments and Businesses

A high-level conceptualisation of information sharing is presented in the Fig. 1. In the relationship with businesses regarding the market, the government has main function to maintain the market by ensuring competitiveness and equal opportunity for firms. The governments (could be national, regional or local level) create regulations, for example regarding trading or fiscal policy, which should protect the customers, the employees, companies and investors. These regulations are then integrated by the private organisations in their routines, in trading activities or other companies' actions. As an assurance that these businesses activities comply with regulations, the companies must report. These reports are then evaluated and analysed by the public organisations. 


\section{Information Sharing Arrangement}

According to Orlikowski [24], technology adaptation and organisation affects each other. Organisational setting and condition may need to be restructured by adapting technology. Organisation, on the other hand, have a privilege to select some technologies in accordance with their objectives, in which could affect the diffusion of those technologies in internal organisation and the market. Further, study from Tiwana and Konsynski [25] provided explanation about how the interplay between architecture and IT governance ensures the use of IT in supporting organisational objective. From a different perspective, the institutional arrangement proposed by Koppenjan and Groenewegen [26] which "designed to coordinate specific transactions among multiple actors concerning labour, capital, intermediate goods, information and the like" $[26$, p.246]. For the IOS, this arrangement is important to facilitate the functioning of the network.

These three approaches are used to conceptualise the arrangement, which is defined as the interplay between architecture and governance of interorganisational system which facilitate information sharing. The importance of information sharing arrangement has been discussed in previous studies. As an example, four essential components of cross-boundary information sharing developed by Gil-Garcia J.R. [27] consists of an organised setting between the infrastructure, shared and standardised data, and trusted social network. Another example, principles in implementing the IOS proposed by Fedorowicz et al. [28] were also highlighting the need of IOS arrangement which encompasses organisational and technological issues.

Further, to have a better understanding of information sharing arrangement, this study will use several design variables: 1) Network Archetype, which comprises the type of infrastructure used to share information; 2) Data Management, including all process of collecting, processing, storing and distributing the data for sharing intention; 3) Process alignment, which related to how the users aligning their business process to support the sharing objectives; and 4) System Governance, which encompass the decision-making structure in the IOS and the communication between users.

\section{Research Methodology}

This paper aims to assess the importance of influential factors in information sharing arrangements. Prior research from Praditya et al. [18] provided 26 factors categorized using Technological, Organisational and Environment (TOE) framework from [29]. Some factors, for example management support and level of adoption, were leftout since they were not relevant for influencing the type of arrangements. Some other factors were combined, including firm size, firm structure, firm governance, firm strategy into organisational compatibilities; standardised data, amount of data and number of transactions into types of data; and all technological factors grouped into IT Capabilities, and IT Compatibility and Interoperability. There are also some factors added based on recent development in the research, for example, perceived benefits, perceived costs, perceived risks, experience and interorganisational relationship. This 
resulted in 16 factors which grouped into factors belonging to the internal organisation, to the interorganisational and to the technical level as shown in Fig. 2

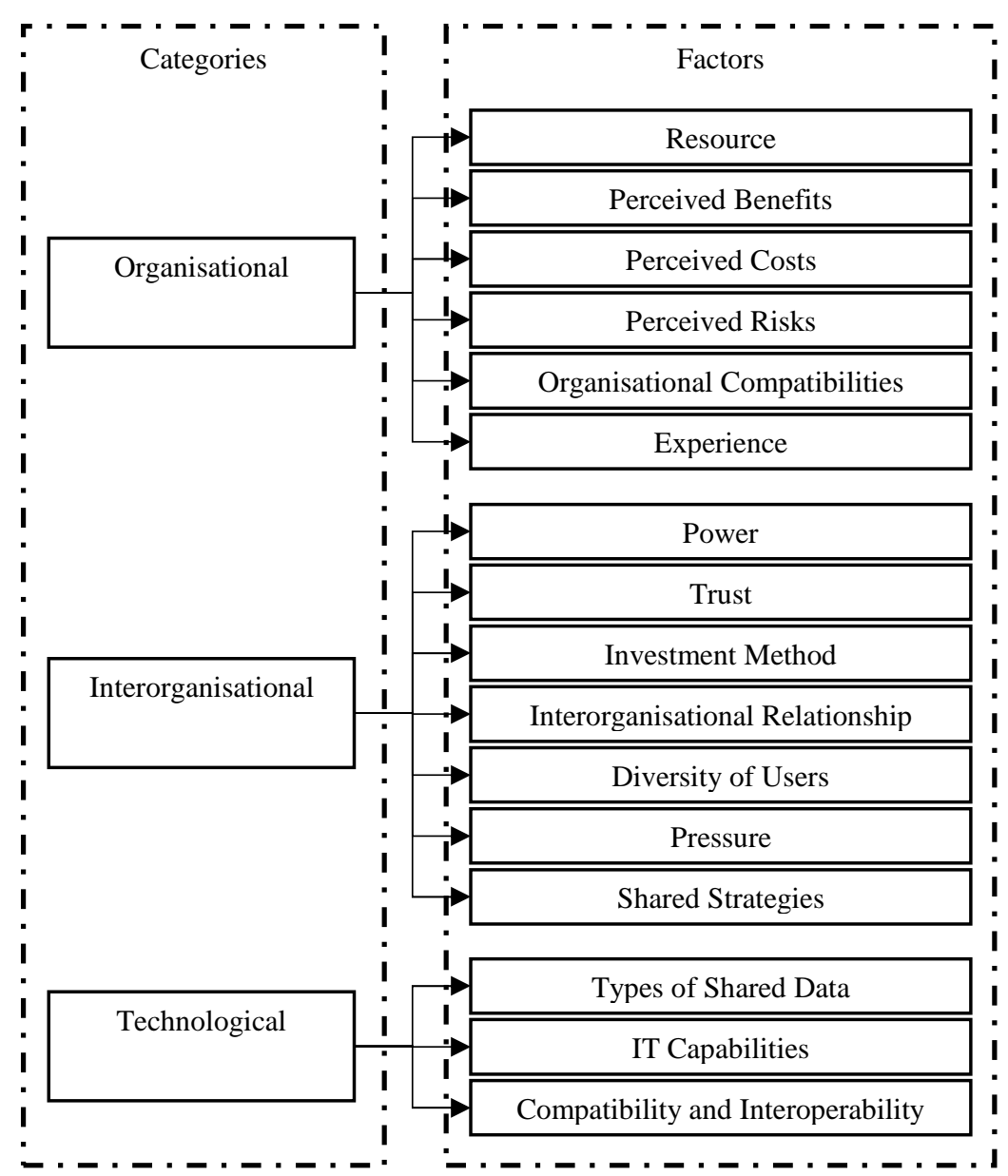

Fig. 2. List of factors influencing information sharing arrangements (modified from [18]).

The BWM was applied as the main method in this study to find the weight of each factor. Data were collected via four expert interviews conducted from April $21^{\text {st }}$ to $26^{\text {th }} 2017$. Each interview took between 45 minutes to 1 hour. The selected respondents have at least 5 years' experience working in the information sharing system. From the interaction during the interviews, these experts showed their broad knowledge regarding the system, especially the ability to analyse the problem from multi-level and multi-contextual perspectives. The overview of the profile of each respondent is presented in Table 1. Based on this selection, this study takes into consideration various viewpoints in prioritising the factors. 
Table 1. Profile of the Experts

\begin{tabular}{l|l|l|l|l}
\hline Variables & A & B & C & D \\
\hline Position & Consultant & Researcher & Researcher & IT Architect \\
\hline Experience & $\begin{array}{l}\text { E-Government } \\
\text { Projects }\end{array}$ & $\begin{array}{l}\text { Open Data Infra- } \\
\text { structure and Infor- } \\
\text { mation Sharing } \\
\text { Mechanism. }\end{array}$ & $\begin{array}{l}\text { Data Sharing } \\
\text { Mechanism to } \\
\text { solve Societal } \\
\text { Problems. }\end{array}$ & $\begin{array}{l}\text { Information Sys- } \\
\text { tems in Private } \\
\text { Organisations. }\end{array}$ \\
\hline Region & South America & Europe & Europe & Europe \\
\hline
\end{tabular}

Interviews were conducted using the steps provided by BWM [21]. However, this study did not follow all the BWM steps because this study aims to weighting the factors, and not to find the best alternative.

The steps to determine the preference and the weight of each factor in this method were as follows: First, a set of criteria (or factors) was defined. In this step, factors that should be used to arrive at a decision were selected. In the second step, the best and worst factors were selected. In this study, each respondent had to select the most important and least important factor in all categories. Because of in this study the factors divided into three groups, it was also necessary to select the best and least important category.

In the third step, each respondent was asked to select the preference of the best factor over all the other factors using a number between one (no preference) and nine (extreme preference). Then, step four was aimed to determine the preference of all the criteria over the worst criterion using the similar way with the previous step. This step performs a role in checking the consistency of respondents' preferences. From these 4 steps, data were collected, and added into 'Microsoft Excel' as the calculation tool. Hence, the weights of factors were determined.

The categorisation aims to simplify the data collection and analysis in the BWM. Instead of comparing 16 factors in one phase, which may confuse the interviewees, this study was divided into two phases. The first phase aimed to determine the weight of factors in each category, or local weighting. At the end of this phase, the weight of each category was determined. The local weight of each factor then multiplied with the weight of correspondent category to determine the global weights. An average of the global weights of the four experts was used as the final results. The result of each phase, the consistency ratio and the patterns or variations in the personal weights of the experts are presented and discussed in the next section.

\section{Results}

As already mentioned in the research methodology, the first step in the first phase aimed to assess each factor locally, or in each category, per expert. Later, the importance of each category is evaluated per expert. As shown in the Table 2, each expert has their own opinion regarding the importance of each factor as they have experiences in different situations. 


\section{Local Weighting}

Table 2. Results of Weighting Factors per Category

\begin{tabular}{|c|c|c|c|c|c|c|c|c|c|c|c|}
\hline & Factor & $\mathbf{A}$ & B & $\mathrm{C}$ & D & & Factor & A & B & $\mathrm{C}$ & D \\
\hline & $\mathrm{O}$ & 0.45 & 0.31 & 0.25 & 0.57 & \multirow{7}{*}{ 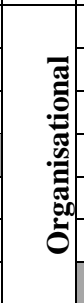 } & $\mathrm{R}$ & 0.15 & 0.12 & 0.27 & 0.12 \\
\hline$=1$ & IO & 0.45 & 0.58 & 0.42 & 0.29 & & PB & 0.37 & 0.17 & 0.27 & 0.56 \\
\hline 氙 & $\mathrm{T}$ & 0.09 & 0.11 & 0.33 & 0.14 & & PC & 0.37 & 0.11 & 0.21 & 0.08 \\
\hline تै & Ksi* & 0.00 & 0.03 & 0.08 & 0.00 & & PR & 0.00 & 0.52 & 0.10 & 0.05 \\
\hline \multirow{8}{*}{ 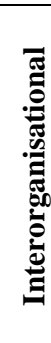 } & $\mathrm{P}$ & 0.29 & 0.10 & 0.19 & 0.22 & & OC & 0.12 & 0.05 & 0.11 & 0.05 \\
\hline & $\mathrm{T}$ & 0.17 & 0.46 & 0.09 & 0.15 & & $\mathrm{E}$ & 0.00 & 0.04 & 0.04 & 0.13 \\
\hline & $\mathrm{I}$ & 0.03 & 0.18 & 0.42 & 0.11 & & Ksi* & 0.37 & 0.19 & 0.06 & 0.18 \\
\hline & IOR & 0.37 & 0.11 & 0.09 & 0.05 & \multirow{5}{*}{ 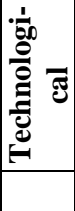 } & TD & 0.08 & 0.70 & 0.33 & 0.09 \\
\hline & DoU & 0.02 & 0.04 & 0.07 & 0.06 & & Cap & 0.29 & 0.10 & 0.33 & 0.32 \\
\hline & IP & 0.08 & 0.06 & 0.09 & 0.08 & & $\mathrm{CI}$ & 0.63 & 0.20 & 0.33 & 0.59 \\
\hline & SS & 0.03 & 0.05 & 0.05 & 0.33 & & $\mathrm{Ksi}^{*}$ & 0.25 & 0.10 & 0.00 & 0.05 \\
\hline & $\mathrm{Ksi}^{*}$ & 0.21 & 0.12 & 0.15 & 0.10 & & & & & & \\
\hline
\end{tabular}

For the Organisational factors, the perceived benefits is considered as the most important factor for almost all experts, excluded expert B which considered this factor as the second most important factor after perceived risks. On the other hand, perceived risks and organisational compatibilities are selected as the least important factors.

For the Interorganisational factors, the experts have different opinion regarding the most influential factor. Interorganisational relationship is selected by expert $\mathrm{A}$; trust is selected by expert $\mathrm{B}$; investment is selected by expert $\mathrm{C}$; and shared strategies is selected by expert $\mathrm{D}$. This suggests that there is no dominating factor in this category.

Regarding the Technological factors, expert A and D have similar opinions, they consider compatibility and interoperability as the main factor, while expert B select type of data as the most important factor. For this category, expert $\mathrm{C}$ found it difficult to select the best criteria and gave all factors the same importance.

In the last step of local weighting, all experts were asked to rank the importance of the category. All experts agreed that technological factors are less important for influencing the information sharing arrangement. Expert B and C selected Interorganisational as the most influential category, while expert D picked out Organisational. In this step, expert A considered both Organisational and Interorganisational as the most important category.

In addition, the BWM results of this local weighting also shows the consistency ratio (CR) of each expert in each category. CR is determined by dividing the Ksi from the BWM results (in Table 2) with the maximum possible of Ksi for the number of factors (consistency index) (in Table 3). The CR is ranging from 0 to 1 . The lower $\mathrm{CR}$ means more consistent of the comparisons, hence more reliable results. The CR 
for this research is shown in the Table 4 below. The average CR per expert shows that, in general, all experts has CR close to zero which means the BWM results used in this research are consistent and reliable.

Table 3. Consistency Index based on the number of criteria [30]

\begin{tabular}{l|l|l|l|l|l|l|l|l|l}
\hline$\alpha$ & 1 & 2 & 3 & 4 & 5 & 6 & 7 & 8 & 9 \\
\hline Consistency Index & $\mathbf{0 . 0 0}$ & $\mathbf{0 . 4 4}$ & $\mathbf{1 . 0 0}$ & $\mathbf{1 . 6 3}$ & $\mathbf{2 . 3 0}$ & $\mathbf{3 . 0 0}$ & $\mathbf{3 . 7 3}$ & $\mathbf{4 . 4 7}$ & $\mathbf{5 . 2 3}$ \\
\hline
\end{tabular}

Table 4. Consistency Ratio of each expert

\begin{tabular}{l|l|l|l|l}
\hline Consistency ratio & A & B & C & D \\
\hline Organisational & 0.12 & 0.06 & 0.02 & 0.06 \\
\hline Interorganisational & 0.06 & 0.03 & 0.04 & 0.03 \\
\hline Technological & 0.25 & 0.10 & 0.00 & 0.05 \\
\hline Average & $\mathbf{0 . 1 1}$ & $\mathbf{0 . 0 6}$ & $\mathbf{0 . 0 4}$ & $\mathbf{0 . 0 3}$ \\
\hline
\end{tabular}

The local weights of all factors and the weights of the categories then will be used to calculate the global weights of all factors. These results are presented in the next part.

\section{Global Weighting}

The global weighting of each factor calculated by multiplying the weight of each factor and the weight of its corresponding category. The final calculation of global weighting is shown in Table 5. Dark grey indicates the most important factor(s) for each expert, while light grey indicates their top-5 important factors. The results show that the importance factors of each experts varied which might be explained by the variety of experiences with the IOS and their background. The variations can be seen in the selection of Top-5 influential factors per each expert and the weight per factor.

Table 5. Results of the Global Weighting Phase

\begin{tabular}{c|l|l|l|l|l}
\hline Factors & $\mathrm{A}$ & $\mathrm{B}$ & $\mathrm{C}$ & $\mathrm{D}$ & Avg. \\
\hline $\mathrm{PB}$ & 0.17 & 0.05 & 0.07 & 0.32 & 0.15 \\
\hline $\mathrm{T}$ & 0.08 & 0.27 & 0.04 & 0.04 & 0.11 \\
\hline $\mathrm{P}$ & 0.13 & 0.06 & 0.08 & 0.06 & 0.08 \\
\hline $\mathrm{I}$ & 0.02 & 0.10 & 0.17 & 0.03 & 0.08 \\
\hline $\mathrm{PC}$ & 0.17 & 0.03 & 0.05 & 0.04 & 0.07 \\
\hline $\mathrm{IOR}$ & 0.17 & 0.07 & 0.04 & 0.01 & 0.07 \\
\hline $\mathrm{CI}$ & 0.06 & 0.02 & 0.11 & 0.08 & 0.07 \\
\hline $\mathrm{R}$ & 0.07 & 0.04 & 0.07 & 0.07 & 0.06 \\
\hline PR & 0.00 & 0.16 & 0.03 & 0.03 & 0.05 \\
\hline $\mathrm{TD}$ & 0.01 & 0.08 & 0.11 & 0.01 & 0.05 \\
\hline Cap & 0.03 & 0.01 & 0.11 & 0.05 & 0.05 \\
\hline SS & 0.02 & 0.03 & 0.02 & 0.09 & 0.04 \\
\hline
\end{tabular}




\begin{tabular}{l|l|l|l|l|l}
\hline $\mathrm{IP}$ & 0.04 & 0.03 & 0.04 & 0.02 & 0.03 \\
\hline $\mathrm{OC}$ & 0.06 & 0.01 & 0.03 & 0.03 & 0.03 \\
\hline $\mathrm{E}$ & 0.00 & 0.01 & 0.01 & 0.07 & 0.02 \\
\hline $\mathrm{DoU}$ & 0.01 & 0.02 & 0.03 & 0.02 & 0.02 \\
\hline
\end{tabular}

The average weights of criteria from all experts shows that perceived benefits, trust, power, investment method, perceived costs, interorganisational relationship, and compatibility and interoperability are the most important factors influencing information sharing arrangement. These factors are the focus of the next section.

\section{Discussion}

The objective of this paper is to assess the importance of factors influencing information sharing arrangement. BWM provided a structured approach to weighting each factor based on experts' opinions. Based on the average calculation of global weighting by each expert, seven most important factors were selected: two factors are included in organisational, four factors are from interorganisational and one factor is from technological. Three of the top-ranking factors are related to economic aspects, including perceived costs, investment and perceived benefits; although perceived benefits could also be measured by other parameters. The other three factors are about the intangible factors, including power, trust and interorganisational relationship. Only one factor categorized as technological factors which implies the experts rate this category is not as challenging as the other two factors.

Perceived benefits is selected as the most important factor of the information sharing arrangement. This factor has often been found as a significant factor in IT adoption [31, 32], including in the adoption of EDI [33]. The expert from private organisation was heavily prioritising this factor even though it is not straightforward to quantify perceived benefits. This may reflect the main motivation of private organisation in the economic aspect of technology adoption. In business-and-government IOS, some benefits might have perceived as less prominent by businesses in comparison to in business-and-business IOS. Example of such benefits are the strengthening customer and business partner relationship [33].

IOS depends on the power relation between involved users [34]. A powerful party can dictate on how the infrastructure should be developed and what kind of governance should be created for the IOS. In the business-and-government setting, government agencies may be considered as the powerful players, but also market leaders or big companies might have more power. Power may also dependent on the investment method being used. Usually, higher investments correspondent with the higher power in system-related decision-making. Power can be used to accelerate the decisionmaking process; however, this may also lead to unwillingness of some potential users to involve in the information sharing. The importance of power in the information sharing arrangements or IOS is widely recognized, see for example [35], [36] and [37]. 
Interorganisational trust is defined as "a company's belief that another company will perform actions that will result in positive outcomes, as well as not taking unexpected actions that would result in negative outcomes for the company" [38, p.522]. It is considered as a control mechanism of interorganisational relationship [39]. Trust influences the information sharing arrangements for example in the development of a decentralised system. This network archetype requires higher-level trust compare to a centralised system. In the implementation of Standard Business Reporting (SBR) as an example, trust is reflected in the strong contribution of involved users in the decision-making process [18].

The choice of network archetype can be influenced by the investment method. For example, using the public-private partnership for financing the implementation project may lead to centralisation, which makes the investment easier to manage. In many cases of IOS implementation, the main investor is the government. Because of the government has strong resemblance in centralisation, this may lead to the adoption of centralisation system. The importance of investment method in the IOS adoption is consistent with the findings from [40] and [41].

Perceived costs were found as a significant factor in IOS adoption [33, 42]. Perceived costs is not only determined during the implementation project, but also during the use and maintenance of the system. Higher costs may be perceived in the implementation of centralised system, especially if the organisation need to improve their internal IT system in order to be compatible with the IOS. However, during the use of the system, centralisation may imply less costs. This kind of trade-off need to be considered carefully by the involved parties.

To achieve objectives which may transcend the organisational boundary and difficult to resolve by individual organisation, it is necessary to develop and maintain the interorganisational relationship [43]. Related to the information sharing and IOS adoption, the established interorganisational relationship plays an important role as discussed by Praditya et al. [18]. In the case of SBR implementation, the interorganisational relationship between Tax Office and its auditees influences the adoption of previous system's governance to the new system's governance. The adoption of previous system's governance was beneficial in reducing the conflict which potentially occurs, especially, during the early phase of implementation project.

Compatibility and interoperability were found as one of the significant factor in the adoption of information sharing and IOS [44, 45]. The importance of this factor can be seen in the implementation of SBR. Standardisation of data, technology and processes are needed to deal with the heterogeneity and the fragmentation of existing IIT systems owned by involved users [18]. This compatibility and interoperability within the system can resulted in the decision of using certain network archetype.

\section{Conclusions}

This study aimed to derive factors of information sharing arrangements by assessing the importance of factors influencing information sharing between public and private 
organisations identified from previous study. To achieve the objective, BWM was applied in the experts' opinions analysis.

From the seven most important factors: two factors are from the organisational category; four factors are from interorganisational category; and one factor is from technological category. These factors are: perceived benefits, trust, power, investment method, perceived costs, interorganisational relationship, and compatibility and interoperability. The results of this study also showed the different opinions from experts which may influenced by their background and experience in information sharing. While other experts selected various of important factors, the expert from private organisation emphasized the importance of perceived benefits above the other factors. Further, the results are found to be consistent with the prior studies in the interorganisational information sharing and IOS adoption.

The results of this study can be used in multiple ways. First, the users and developers of the system can understand which factors that are relatively important and ensure they are fulfilled during the development of information sharing system. Second, the differences between private and public organisations' viewpoints can be used as inputs for developing a strategy, for example, to create different narratives when providing information to a particular organisation. Third, scientifically, the results can be used as an input for future studies if, for example, the factors are tested using other MCDM method or other statistical analysis. Different statistical analysis may capture the possibilities of mutually influence and dependencies between factors, for example, between trust and power or between perceived costs, benefits and investment.

However, there are also some limitations. Although the BWM does not require a minimum number of respondents, there might be an issue regarding the generality and reliability of the results. The results could be better if the stakeholder analysis were also applied. Hence, comprehensive viewpoints from both businesses and governments would be better captured. Another limitation is the absence of alternatives, as one of the main elements for MCDM, and this resulted in the BWM was not being fully utilised.

\section{References}

1. Janssen, M., H. van der Voort, and A. Wahyudi, Factors influencing big data decisionmaking quality. Journal of Business Research, 2017. 70: p. 338-345.

2. Treku, D.N. and G.O. Wiredu, Information Systems Implementation and Structural Adaptation in Government-Business Inter-Organization. 2016.

3. Pardo, T.A., et al. Modeling the social \& technical processes of interorganizational information integration. in System Sciences, 2004. Proceedings of the 37th Annual Hawaii International Conference on. 2004. IEEE.

4. Samaddar, S., S. Nargundkar, and M. Daley, Inter-organizational information sharing: The role of supply network configuration and partner goal congruence. European Journal of Operational Research, 2006. 174(2): p. 744-765.

5. Dawes, S.S., Interagency information sharing: Expected benefits, manageable risks. Journal of Policy Analysis and Management, 1996. 15(3): p. 377-394. 
6. Barrett, S. and B. Konsynski, Inter-organization information sharing systems. MIS Quarterly, 1982: p. 93-105.

7. Landsbergen Jr, D. and G. Wolken Jr, Realizing the promise: Government information systems and the fourth generation of information technology. Public Administration Review, 2001. 61(2): p. 206-220.

8. Yang, T.-M. and T.A. Maxwell, Information-sharing in public organizations: A literature review of interpersonal, intra-organizational and inter-organizational success factors. Government Information Quarterly, 2011. 28(2): p. 164-175.

9. Gil-Garcia, J.R. and D.S. Sayogo, Government inter-organizational information sharing initiatives: Understanding the main determinants of success. Government Information Quarterly, 2016.

10. Yang, T.-M. and Y.-J. Wu, Exploring the determinants of cross-boundary information sharing in the public sector: An e-Government case study in Taiwan. Journal of Information Science, 2014. 40(5): p. 649-668.

11. Sayogo, D.S. and J.R. Gil-Garcia. Understanding the determinants of success in interorganizational information sharing initiatives: results from a national survey. in Proceedings of the 15th Annual International Conference on Digital Government Research. 2014. ACM.

12. Olesen, P., et al., Framework for Information Sharing in a Small-to-Medium Port System Supply Chain, in Advances in Production Management Systems. Innovative and Knowledge-Based Production Management in a Global-Local World, B. Grabot, et al., Editors. 2014, Springer Berlin Heidelberg. p. 257-264.

13. Engel, T., et al. Investigating Information Sharing Behavior in Supply Chains: Evidence from an Embedded Single Case Study. in System Sciences (HICSS), 2014 47th Hawaii International Conference on. 2014.

14. Fedorowicz, J., J.L. Gogan, and C.B. Williams, A collaborative network for first responders: Lessons from the CapWIN case. Government Information Quarterly, 2007. 24(4): p. 785-807.

15. Kożuch, B. and K. Sienkiewicz-Małyjurek, Information sharing in complex systems: a case study on public safety management. Procedia-Social and Behavioral Sciences, 2015. 213: p. $722-727$.

16. Crowther, K.G., Understanding and Overcoming Information Sharing Failures. Journal of Homeland Security and Emergency Management, 2014. 11(1): p. 131-154.

17. Lee, J., et al., Group value and intention to use-A study of multi-agency disaster management information systems for public safety. Decision Support Systems, 2011. 50(2): p. 404-414.

18. Praditya, D., M. Janssen, and R. Sulastri, Determinants of Business-to-Government Information Sharing Arrangements. Electronic Journal of E-Government, 2017. 15(1): p. 44-55.

19. Bharosa, N., et al., Developing Multi-sided Platforms for Public-Private Information Sharing: Design Observations from Two Case Studies, in Proceedings of the 14th Annual International Conference on Digital Government Research. 2013, ACM: New York, NY, USA. p. 146-155.

20. Praditya, D. and M. Janssen. Benefits and Challenges in Information Sharing Between the Public and Private Sectors. in Academic Conferences Limited. 2015. 
21. Rezaei, J., Best-Worst Multi-Criteria Decision-Making Method. Omega, 2015. 53: p. 4957.

22. Rezaei, J., et al., A supplier selection life cycle approach integrating traditional and environmental criteria using the best worst method. Journal of Cleaner Production, 2016. 135: p. 577-588.

23. Gil-Garcia, J.R., S.A. Chun, and M. Janssen, Government information sharing and integration: Combining the social and the technical. Information Polity, 2009. 14(1,2): p. $1-10$.

24. Orlikowski, W.J., The duality of technology: Rethinking the concept of technology in organizations. Organization science, 1992. 3(3): p. 398-427.

25. Tiwana, A. and B. Konsynski, Complementarities Between Organizational IT Architecture and Governance Structure. Information Systems Research, 2010. 21(2): p. 288-304.

26. Koppenjan, J. and J. Groenewegen, Institutional design for complex technological systems. International Journal of Technology, Policy and Management, 2005. 5(3): p. 240-257.

27. Gil-Garcia J.R., P.T.A., and Burke G.B., Conceptualizing Information Integration in Government, in E-Government: Information, Technology, and Transformation, H.J. Scholl, Editor. 2010, M.E. Sharpe: Armonk, NY. p. 179-202.

28. Fedorowicz, J., et al., Design observations for interagency collaboration. Government Information Quarterly, 2014. 31(2): p. 302-316.

29. Depietro, R., E. Wiarda, and M. Fleischer, The context for change: Organization, technology and environment. The processes of technological innovation, 1990. 199(0): p. 151-175.

30. Rezaei, J., Best-worst multi-criteria decision-making method: Some properties and a linear model. Omega, 2016. 64: p. 126-130.

31. Iacovou, C.L., I. Benbasat, and A.S. Dexter, Electronic data interchange and small organizations: adoption and impact of technology. MIS quarterly, 1995: p. 465-485.

32. Akbulut, A.Y., et al., To share or not to share? Examining the factors influencing local agency electronic information sharing. International Journal of Business Information Systems, 2009. 4(2): p. 143-172.

33. Chau, P.Y. and K.L. Hui, Determinants of small business EDI adoption: an empirical investigation. Journal of Organizational Computing and Electronic Commerce, 2001. 11(4): p. 229-252.

34. Boonstra, A. and J. de Vries, Analyzing inter-organizational systems from a power and interest perspective. International Journal of Information Management, 2005. 25(6): p. 485-501.

35. Hart, P. and C. Saunders, Power and trust: Critical factors in the adoption and use of electronic data interchange. Organization science, 1997. 8(1): p. 23-42.

36. Chang, C.L.-h., The relationship among power types, political games, game players, and information system project outcomes-A multiple-case study. International Journal of Project Management, 2013. 31(1): p. 57-67.

37. Nicholls, A. and B. Huybrechts, Sustaining Inter-organizational Relationships Across Institutional Logics and Power Asymmetries: The Case of Fair Trade. Journal of Business Ethics, 2016. 135(4): p. 699-714. 
38. Neergaard, H. and J.P. Ulhøi, Government agency and trust in the formation and transformation of interorganizational entrepreneurial networks. Entrepreneurship Theory and Practice, 2006. 30(4): p. 519-539.

39. Gil-Garcia, J.R., et al. Trust in Government Cross-Boundary Information Sharing Initiatives: Identifying the Determinants. in System Sciences (HICSS), 2010 43rd Hawaii International Conference on. 2010.

40. Han, K., R.J. Kauffman, and B.R. Nault, Relative importance, specific investment and ownership in interorganizational systems. Information Technology and Management, 2008. 9(3): p. 181-200.

41. Iubatti, D., F. Masciarelli, and A. Simboli, Inter-organizational design: exploring the relationship between formal architecture and ICT investments, in Evolving towards the internetworked enterprise. 2010, Springer. p. 163-174.

42. Lin, H.-F., Understanding the determinants of electronic supply chain management system adoption: Using the technology-organization-environment framework. Technological Forecasting and Social Change, 2014. 86: p. 80-92.

43. Cheng, J.-H., Inter-organizational relationships and information sharing in supply chains. International Journal of Information Management, 2011. 31(4): p. 374-384.

44. Premkumar, G., K. Ramamurthy, and M. Crum, Determinants of EDI adoption in the transportation industry. European Journal of Information Systems, 1997. 6(2): p. 107121.

45. Tornatzky, L.G. and K.J. Klein, Innovation characteristics and innovation adoptionimplementation: A meta-analysis of findings. Engineering Management, IEEE Transactions on, 1982. EM-29(1): p. 28-45. 